\title{
Burden of hypothyroidism amongst type 2 diabetics and hypertensives in Lucknow: A cross sectional study
}

Saurabh Kashyap ${ }^{1}$, Mohammad Suhail Khan ${ }^{2}$, Anas Ahmad Khan ${ }^{3}$, M Z Idris ${ }^{4}$, Ausaf Ahmad ${ }^{5}$, Sheetal Verma6

${ }^{1}$ Associate Professor, Integral Institute of Medical Sciences and Research, Integral University, Lucknow, Uttar Pradesh; ${ }^{2}$ Assistant Professor, Integral Institute of Medical Sciences and Research, Integral University, Lucknow, Uttar Pradesh; ${ }^{3}$ Assistant Professor, Integral Institute of Medical Sciences and Research, Integral University, Lucknow, Uttar Pradesh; ${ }^{4}$ Professor, Integral Institute of Medical Sciences and Research, Integral University, Lucknow, Uttar Pradesh; ${ }^{5}$ Assistant Professor, Integral Institute of Medical Sciences and Research, Integral University, Lucknow, Uttar Pradesh; ${ }^{6}$ Associate Professor, King George`s Medical University, Lucknow, Uttar Pradesh

\begin{tabular}{|l|l|l|l|l|l|l|l|}
\hline Abstract & Introduction & Methodology & Results & Conclusion & References & Citation & Tables/ Figures \\
\hline
\end{tabular}

\section{Corresponding Author}

Dr Mohammad Suhail Khan, Assistant Professor, Integral Institute of Medical Sciences and Research, Integral University, Lucknow, Uttar Pradesh

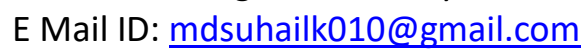

\section{Citation}

Kashyap S, Khan MS, Khan AA, Idris MZ, Ahmad A, Verma S. Burden of hypothyroidism amongst type 2 diabetics and hypertensives in Lucknow: A cross sectional study. Indian J Comm Health. 2020;32(4):643-646. https://doi.org/10.47203/IJCH.2020.v32i04.006

Source of Funding: Nil Conflict of Interest: None declared

\section{Article Cycle}

Received: 20/06/2020; Revision: 14/07/2020; Accepted: 05/08/2020; Published: 31/12/2020

This work is licensed under a Creative Commons Attribution 4.0 International License.

\section{Abstract}

Background: The prevalence of hypothyroidism is reported in $4 \%-5 \%$ of population in the developed world, while in Indian population it is reported in around one in ten adults. Aims \& Objectives: This study was conducted to determine the prevalence of hypothyroidism in Indian patients with T2DM and hypertension. Material and methods: In this cross-sectional observational study, amongst adults who were aged 18 years and above and diagnosed T2DM, HTN, and T2DM + HTN who resided in the field practice areas of the Urban Health Training Centre of the Department of Community Medicine, Integral institute of medical sciences and research, Lucknow, India. The results were summarized by descriptive statistics. Results: Out of 300 persons questioned, 159 (53.0\%) were females and $141(47.0 \%)$ were males. It was found that the mean age of the overall population was $53.1 \pm 11.3$ years, mean and standard deviation of thyroid function and glycemic indicators test, observed that the levels of fT3, fT4, TSH, and glycemic indicators like FPG, PPG and HbA1c were identical. Conclusion: Subclinical hypothyroid subjects should be regularly screened for HTN. Elderly patients had higher proportion of thyroid dysfunction.

\section{Keywords}

Type II Diabetes Mellitus; Hypertension; Hypothyroidism; Prevalence

\section{Introduction}

Hypothyroidism is one of the most common endocrine abnormality encountered and have a significant health effect in population of age group above 18 years. Several studies have shown the association of hypertension (HTN) with subclinical hypothyroidism in adults (1). Hypothyroidism can present itself as an overt state of myxoedema, endorgan effects, and multisystem failure (2). The prevalence of hypothyroidism was reported in four to five percent of population in the developed world, while in Indian population it was reported in around 
one in ten adults (3). The association between the diabetes and hypothyroidism has long been recognized, although the prevalence of thyroid dysfunction in diabetic population varies widely between various studies. Enhanced sensitivity and specificity of TSH has greatly enhanced assessment of thyroid functions (4). Thyroid dysfunction (both hypothyroidism and hyperthyroidism) may increase the risk of HTN (5). However, it is still controversial whether mild thyroid dysfunction, such as subclinical hypothyroidism, affects blood pressure. Subjects with subclinical hypothyroidism have elevated thyroid-stimulating hormone (thyrotropin, TSH) levels and normal free thyroxine (T4) levels (6). Studies have also suggested an association between subclinical hypothyroidism and HTN, which has been subsequently confirmed by some, but not all, large cross-sectional and case-control studies $(7,8)$.

\section{Aims \& Objectives}

To determine the prevalence of hypothyroidism in Indian population with T2DM and HTN.

\section{Material \& Methods}

Study type: The cross-sectional study

Study population: Adults aged 18 years and above, who resided in the rural health Centre, situated in Sansarpur catering to a huge urban population of the Lucknow city.

Study area: Field practice areas of the Rural Health Training Centre of the Department of Community Medicine, Integral institute of medical sciences and research, Lucknow, India.

Study duration: December 2018 to December 2019. Sample size: The sample size was calculated by the formula $4 \mathrm{PQ} / \mathrm{L} 2$ where $\mathrm{P}$ is the prevalence (8); $\mathrm{Q}$ is $100-P$ and $L$ is the absolute precision i.e. $5 \%$. We enrolled 300 subjects with T2DM and/or HTN, who visited the rural health training centre. One Patient each with T2DM, HTN, and T2DM + HTN were enrolled in the equal proportion.

Inclusion criteria: All consenting person suffering from T2DM, HTN and T2DM along with HTN with age above 18 years.

Exclusion criteria: All person who were not having any malignancy within last 5 years, who were not having fever, viral infections, neck pain, who were taking any drugs that might interfere with thyroid functions.

\section{Operational definition:}

Hypertension: Clinical HTN was defined as a mean of at least two readings of $140 \mathrm{mmHg}$ systolic blood pressure (SBP) and/or $90 \mathrm{mmHg}$ diastolic Phase $\mathrm{V}$ blood pressures or greater.

Diabetes mellitus: Abnormal blood sugar was defined as accrual of diabetes, Impaired Glucose Tolerance and Impaired Fasting Glucose. Impaired Glucose Tolerance was calculated using the 1997 ADA fasting glucose criteria (FPG) and the WHO oral glucose tolerance test criteria (9). Thus, by the FPG criteria, values of $>7.0 \mathrm{mmol} / \mathrm{l}(126 \mathrm{mg} \%)$ and 6.1-6.9 $\mathrm{mmol} / \mathrm{l}$ (111-125 $\mathrm{mg} \%$ ) were considered diabetes and IFG respectively, and by the $2 \mathrm{hrs}$ polst-glucose criteria, values > $11.1 \mathrm{mmol} / \mathrm{l}$ (>200 $\mathrm{mg} \%$ ) and 7.8$11.0 \mathrm{mmol} / \mathrm{l}$ (140-199 mg\%) were considered diabetes and IGT, respectively.

Overweight/Obese: A person was considered overweight if $\mathrm{BMI}$ was $>23$ and $<25 \mathrm{~kg} / \mathrm{m} 2$ and obese if BMI was $>25 \mathrm{~kg} / \mathrm{m} 2$.(10)

Overt hypothyroidism/Subclinical hypothyroidism: Person was classified to have overt hypothyroidism if the level of TSH was $>4.50 \mu \mathrm{lU} / \mathrm{mL}, \mathrm{fT} 4<0.8 \mathrm{ng} / \mathrm{dL}$, and $\mathrm{fT} 3<1.4 \mathrm{pg} / \mathrm{mL}$ and subclinical hypothyroidism (Sch) if the level of TSH was $>4.50 \mu \mathrm{IU} / \mathrm{mL}$, fT4 was $0.8-1.8 \mathrm{ng} / \mathrm{dL}$, and fT3 was $1.4-4.4 \mathrm{pg} / \mathrm{mL}$.(11)

Ethical approval: Ethical clearance for the study was obtained from the university ethical committee.

Consent: Informed consent was obtained verbally and written both from each study participant after reading a standard written description of the purpose and procedure of the study.

Data analysis: Data entry and statistical analysis were performed using the Microsoft Excel and SPSS windows version 16.0 software. Statistical significance was taken ( $p$ value $<0.05$ ).

\section{Results}

The present study was conducted amongst 300 people (T2DM: 100; HTN: 100; T2DM + HTN: 100), who resided in the field practice areas of the Urban Health Training Centre of the Department of Community Medicine, Integral institute of medical sciences and research, Lucknow, India. The following observations were obtained.

[Table 1] summarizes the distribution of study subjects with respect to age and gender. In the overall population, 159 (53.0\%) were females and 141 (47.0\%) were males. The mean age of the overall population was $53.1 \pm 11.3$ years. Mean age of patients belonging to type-II diabetes mellitus was less as compared to others.

[Table 2] depicts the mean and standard deviation of thyroid function and serum glucose test levels. It was 
observed that the levels of fT3, fT4, TSH, and glycemic indicators like FPG, PPG and HbA1c were identical. Variation of thyroid function test was higher in TSH level and minimum variation in fT4 levels between type-II diabetes mellitus and hypertensive patients.

[Table 3] Out of 89 patients with hypothyroidism, 67 had overt hypothyroidism and 22 had $\mathrm{SCH}$. A total of $89 / 300(29.7 \%)$ patients had hypothyroidism, out of which $25(25.0 \%)$ cases were reported in patients with T2DM, 35 (35.0\%) in patients with hypertension, and 29 (29.0\%) in patients with T2DM with hypertension.

\section{Discussion}

This study was to determine the proportion of hypothyroidism in patients with T2DM and HTN. It clearly reported a high prevalence of hypothyroidism in patients with T2DM (25.0\%), hypertension (35.0\%), and T2DM with hypertension (29.0\%) compared with prevalence noted by the study conducted elsewhere in the country. Many studies have found that the prevalence of hypothyroidism in patients with T2DM was $11 \%-23 \%(12,13,14,15,16)$ Furthermore, hypothyroidism and hyperthyroidism, could also probably increase the likely risk of hypertension. $(17,18)$ Although, the role of subclinical hypothyroidism on blood pressure is still debatable but many patients suffering from subclinical hypothyroidism exhibits raised thyroidstimulating hormone (thyrotropin, TSH) levels and normal free thyroxine (T4) levels. (19) Many studies suggested a detrimental effect of subclinical hypothyroidism on heart function (2). Diabetes and hypertension have shown a significant association with hypothyroidism (20). Studies have shown that the serum T3 levels, TSH levels have a strong effect on blood glucose levels (16). As the duration of diabetes and hypertension in elderly and obese patients increases the burden of hypothyroidism also rises (8). In present study mean age of the overall population were $53.1 \pm 11.3$ years. Mean age of patients belongs to type-II diabetes mellitus were less as compared to HTN. In addition, Flatau and Trougouboff found that elderly population have higher prevalence of hypothyroidism and hypertension, and these comorbidities can easily be prevented by managing diet and starting oral anti diabetic drugs.

\section{Conclusion}

The proportion of thyroid dysfunction is found to be higher in elderly age group. Study also reports high prevalence of hypothyroidism in patients with T2DM, hypertension, and T2DM + HTN. The person with subclinical hypothyroid subjects should be screened regularly for HTN.

\section{Recommendation}

Patients with subclinical hypothyroidism should be told about the co morbidities associated with hypothyroidism. Regular screening of patients with hypertension/type-II diabetes mellitus for hypothyroidism is highly recommended as the patients of metabolic disease should be treated as early as possible so as to avoid any impending complications, this will further facilitate to formulate the management strategies.

\section{Limitation of the study}

The study was conducted at rural health training centre, it could have been conducted at multi-centric level. The sample size taken in the study was small, hence a bigger sample size would be more effective in changing the levels of prevention.

\section{Relevance of the study}

The proper management of hypothyroidism in elderly population is quite pivotal. As females were more prone to get hypothyroid problems hence early diagnosis and thereby prompt treatment could prove to be very effective.

\section{Authors Contribution}

All authors have contributed towards conception and design, data analysis and interpretation. The article has been drafted and critically reviewed, before given for final approval for the publication.

\section{References}

1. Saito I, Ito K, Saruta T. Hypothyroidism as a cause of hypertension. Hypertension. 1983;5(1):112-5. doi: 10.1161/01.hyp.5.1.112. PMID:6848458.[PubMed].

2. Chaker L, Bianco AC, Jonklaas J, Peeters RP. Hypothyroidism. Lancet. 2017 23;390(10101):1550-1562. doi: 10.1016/S01406736(17)30703-1. Epub 2017 Mar 20.PMID: 28336049; PMCID: PMC6619426.[PubMed].

3. Unnikrishnan AG, Kalra S, Sahay RK, Bantwal G, John M, Tewari N. Prevalence of hypothyroidism in adults: An epidemiological study in eight cities of India. Indian J Endocrinol Metab. 2013;17(4):647-52. doi: 10.4103/2230-8210.113755.PMID: 23961480; PMCID: PMC3743364. [PubMed]

4. Ravishankar, SN, Champakamalini, Venkatesh, Mohsin A. prospective study of thyroid - dysfunction in patients with Type 2 diabetes in general population. Archives of Medicine, 2013; 5(1): 1-9. 
INDIAN JOURNAL OF COMMUNITY HEALTH / VOL 32 / ISSUE NO 04 / OCT - DEC 2020

5. Cappola AR, Ladenson PW. Hypothyroidism and atherosclerosis. J Clin Endocrinol Metab. 2003;88(6):2438-44. doi: 10.1210/jc.2003-030398. PMID: 12788839.[PubMed]

6. Helfand M; U.S. Preventive Services Task Force. Screening for subclinical thyroid dysfunction in nonpregnant adults: a summary of the evidence for theU.S. Preventive Services Task Force. Ann Intern Med. 2004 20;140(2):128-41. doi: 10.7326/0003-4819-140-2-200401200-00015. PMID: 14734337. [PubMed].

7. Monzani F, Dardano A, Caraccio N. Does treating subclinical hypothyroidism improve markers of cardiovascular risk? Treat Endocrinol. 2006;5(2):65-81. doi: 10.2165/00024677200605020-00001. PMID: 16542047.[PubMed].

8. Talwalkar P, Deshmukh V, Bhole M. Prevalence of hypothyroidism in patients with type 2 diabetes mellitus and hypertension in India: a cross-sectional observational study. Diabetes, Metabolic Syndrome and Obesity: Targets and Therapy Dovepress. 2019;12 :369-376

9. Alberti KG, Zimmet PZ. Definition, diagnosis and classification of diabetesmellitus and its complications. Part 1: diagnosis and classification of diabetesmellitus provisional report of a WHO consultation. Diabet Med. 1998;15(7):539-53. doi: 10.1002/(SICI)1096-9136(19980 )15:7<539::AIDDIA668>3.0.CO;2-S. PMID: 9686693. [PubMed].

10. Misra A, Chowbey P, Makkar BM, Vikram NK, Wasir JS, Chadha D, Joshi SR, Sadikot S, Gupta R, Gulati S, Munjal YP; Concensus Group. Consensus statementfor diagnosis of obesity, abdominal obesity and the metabolic syndrome for AsianIndians and recommendations for physical activity, medical and surgical management. J Assoc Phsicians India. 2009;57:163-70. PMID: 19582986. [PubMed].

11. Dayan CM. Interpretation of thyroid function tests. Lancet. 2001 24;357(9256):619-24. doi: 10.1016/S01406736(00)04060-5. PMID: 11558500.[PubMed].

12. Demitrost $L$, Ranabir $S$. Thyroid dysfunction in type 2 diabetes mellitus: A retrospective study. Indian J Endocrinol Metab.
[Burden of hypothyroidism] | Kashyap S et al 2012 Dec;16(Suppl 2):S334-5.doi: 10.4103/2230-8210.104080. PMID: 23565418; PMCID: PMC3603066.[PubMed].

13. Han $C$, He X, Xia X, Li Y, Shi X, Shan Z, Teng W. Subclinical Hypothyroidism and Type 2 Diabetes: A Systematic Review and Meta-Analysis. PLoS One. 2015 13;10(8):e0135233. doi: 10.1371/journal.pone.0135233. PMID: 26270348; PMCID: PMC4535849.[PubMed].

14. Devi MA, Singh NS, Singh LS. Thyroid hormone dysfunction in type 2 diabetic patients in urban areas of Manipur. Int J Pharm Sci Int. 2013;2:7-9.

15. Vikram VB, Kanitkar SA, Tamakuwala KK, et al. Thyroid dysfunction in patients with type 2 diabetes mellitus at tertiary care centre. Nat J Med Res. 2013;3:377-380.

16. Uppal V, Vij C, Bedi GK, Vij A, Banerjee BD. Thyroid disorders in patients of type 2 diabetes mellitus. Indian J Clin Biochem. 2013;28(4):336-41. doi:10.1007/s12291-012-0293-9. Epub 2013 Jan 3. PMID: 24426234; PMCID: PMC3783922.[PubMed]

17. Kadiyala R, Peter R, Okosieme OE. Thyroid dysfunction in patients with diabetes: clinical implications and screening strategies. Int J Clin Pract. 2010;64(8):1130-9. doi: 10.1111/j.1742-1241.2010.02376.x. PMID: 20642711. [PubMed]

18. Curnock AL, Dweik RA, Higgins BH, Saadi HF, Arroliga AC. High prevalence of hypothyroidism in patients with primary pulmonary hypertension. Am J Med Sci. 1999;318(5):289-92. doi: 10.1097/00000441-199911000-00001. PMID: 10555089.[PubMed].

19. Turchi F, Ronconi V, di Tizio V, Boscaro M, Giacchetti G. Blood pressure, thyroid-stimulating hormone, and thyroid disease prevalence in primary aldosteronism and essential hypertension. Am J Hypertens. 2011;24(12):1274-9. doi: 10.1038/ajh.2011.144. Epub 2011 Aug 18. PMID: 21850059.[PubMed]

20. Subekti I, Pramono LA, Dewiasty E, Harbuwono DS. Thyroid Dysfunction in Type 2 Diabetes Mellitus Patients. Acta Med Indones. 2017;49(4):314-323. PMID:29348381.[PubMed]

\section{Tables}

TABLE 1 DISTRIBUTION OF STUDY SUBJECTS WITH RESPECT TO AGE AND GENDER

\begin{tabular}{|l|c|c|c|}
\hline & Mge (years) & Female(\%) & Gender \\
\hline T2DM & Mean \pm SD & 44 & 56 \\
\hline HTN & $49.6 \pm 9.8$ & 60 & 40 \\
\hline T2DM + HTN & $52.0 \pm 12.9$ & 55 & 45 \\
\hline Total & $57.6 \pm 11.1$ & 100 & 100 \\
\hline T2DM, type two diabetes mellitus; HTN, Hypertension & $53.1 \pm 11.3$ & & \\
\hline
\end{tabular}

\begin{tabular}{|c|c|c|c|c|c|c|}
\hline & fT3 (pg/ml) & fT4 (ng/dl) & $\mathrm{TSH}(\mu \mathrm{iU} / \mathrm{ml})$ & FPG (mg/dl) & PPG (mg/dl) & HbA1c (\%) \\
\hline T2DM & $3.5 \pm 9.9$ & $0.9 \pm 0.7$ & $3.2 \pm 6.1$ & $151.1 \pm 70.0$ & $214.3 \pm 98.1$ & $8.4 \pm 3.1$ \\
\hline HTN & $3.2 \pm 9.8$ & $1.0 \pm 0.9$ & $3.9 \pm 10.3$ & $93.1 \pm 11.9$ & $114.1 \pm 20.9$ & $6.0 \pm 0.5$ \\
\hline T2DM + HTN & $3.3 \pm 9.3$ & $1.1 \pm 0.6$ & $3.2 \pm 5.9$ & $128.7 \pm 46.1$ & $190.0 \pm 68.9$ & $7.8 \pm 1.7$ \\
\hline Total & $3.3 \pm 9.6$ & $1.0 \pm 0.8$ & $3.4 \pm 7.4$ & $124.3 \pm 42.7$ & $172.8 \pm 62.6$ & $7.4 \pm 1.8$ \\
\hline
\end{tabular}

TABLE 3 PREVALENCE OF HYPOTHYROIDISM IN DIAGNOSED PATIENTS

\begin{tabular}{|l|l|l|l|}
\hline & Overt, $n(\%)$ & SCH, $n(\%)$ & Total, $n(\%)$ \\
\hline T2DM (100) & $19(19.0)$ & $6(6.0)$ & $25(25.0)$ \\
\hline HTN (100) & $26(26.0)$ & $9(9.0)$ & $35(35.0)$ \\
\hline T2DM + HTN (100) & $22(22.0)$ & $7(7.0)$ & $29(29.0)$ \\
\hline Total & $67(22.3)$ & $22(7.3)$ & $89(29.7)$ \\
\hline
\end{tabular}

